\title{
ENERGY PARAMETERS AND FEEDSTOCK MANAGEMENT IN FARM-SCALE BIOGAS PLANTS: SURVEY IN THE NORTH-EAST OF ITALY
}

\author{
Andrea Pezzuolo, Davide Boscaro, Luigi Sartori, Francesco Marinello \\ University of Padova, Italy \\ andrea.pezzuolo@unipd.it
}

\begin{abstract}
Biogas production from agricultural energy crops is considered as a promising alternative to reduce the current dependence on non-renewable energy sources. Among these, Anaerobic Digestion (AD) of different feedstock has proved to be an interesting energy source in rural areas, especially when the AD plants are fed with local available feedstock and the energy generated is used near the plant. Nowadays, more than 1100 agricultural biogas plants are operating in Italy, particularly in the northern regions. In Italy biogas plants are mainly concentrated in Po Valley regions, (Lombardia, Piemonte, Emilia-Romagna and Veneto); although the biogas policy scheme concerns all the country, these regions have a highly productive agricultural system and densely populated urban areas. In this paper, real operative data (gas yield and feedstock management) of 28 farm-scale biogas plants localized in the Po Valley (North-Eastern Italy) are summarized and analyzed to investigate the increasing factors of biogas production and identify the important parameters for further positive developments. The survey results suggest a positive outlook for other crops and agricultural waste integration into the AD supply chain. More than half of the biogas plants present a nominal power higher than $2.2 \mathrm{MW}$ and electric power values that in $60.7 \%$ of the cases amount to $0.999 \mathrm{MWe}$, in order to remain into the dimensional limits and to benefit from the maximum energetic incentive.
\end{abstract}

Keywords: anaerobic digestion, biogas, energy parameters, feedstock management.

\section{Introduction}

Biogas production from energy crops is considered as a promising alternative to reduce the current dependence on non-renewable energy sources [1;2]. Among these, Anaerobic Digestion (AD) of different feedstock has proved to be an interesting energy source in rural areas [3], especially when the AD plants are fed with local available feedstock and the energy generated (i.e. heat) is used near the plant [4].

Biogas plants operate mainly with three types of biomass sources: (i) farm by-products (such as animal slurries, agricultural residues and straw) [5]; (ii) agro-industrial and food industry by-products and residues [6]; (iii) the dedicated biomass produced specifically for energetic purposes [7].

At the end of 2011, the EU primary energy production from AD plants has been more than 10 Mtoe per year, with an increase of almost $20 \%$ compared to 2009 [8]. In the 2011-2013 period, Italian agricultural AD plants have a surprising increase (almost $300 \%$ ), due to a particularly favorable incentive for biogas electric energy generation; in addiction, the biogas plant number has grown from 314 (end of 2010) to 994 (end of 2012) and the electric power from 176 to 756 MW [9].

Nowadays, more than 1100 agricultural biogas plants are operating in Italy, principally in the northern regions [10; 11]. In Italy biogas plants are mainly concentrated in Po Valley regions, (Lombardia, Piemonte, Emilia-Romagna and Veneto); although the biogas policy scheme concerns all the country $[12 ; 13]$, these regions have a highly productive agricultural system and densely populated urban areas [14].

In this paper, real operative data of 28 farm-scale biogas plants localized in the Po Valley (NorthEastern Italy) are summarized and analyzed to investigate the increasing factors of biogas production and identify the important parameters for further positive developments.

\section{Materials and methods}

\section{Biogas Plants Survey}

Gas yield and feedstock management for 28 farm-scale biogas plants localized in the territory of Padova (Northeast Italy) are summarized and analyzed. The survey was carried out in 2014 and considered all the biogas plants with an electrical installed power higher than $250 \mathrm{~kW}$.

Among the plants analyzed, 19 are located in the south of Padova city while the other 9 ones in the north; this means that $67 \%$ of the biogas plants are located in a more suitable area for agricultural 
and livestock activities than in the northern area, where the number of these plants and their size are more restricted (Fig. 1).

This study was based on interviews with the plant owners, where it was possible to define the following aspects:

- Biogas plants characterization by the analysis of powers installed (nominal, thermal, electrical).

- Operative and energetic performance analysis: number of production hours per day, number of production days per year, ordinary and extraordinary down-time intervals (in days) per year, the average of electrical and thermal energy produced in $\mathrm{MWh} \cdot \mathrm{year}^{-1}$.

- Feedstock management: types and quantities of biomass consumed (agricultural, livestock, etc.) also the origin of the same (in-farm or off-farm).

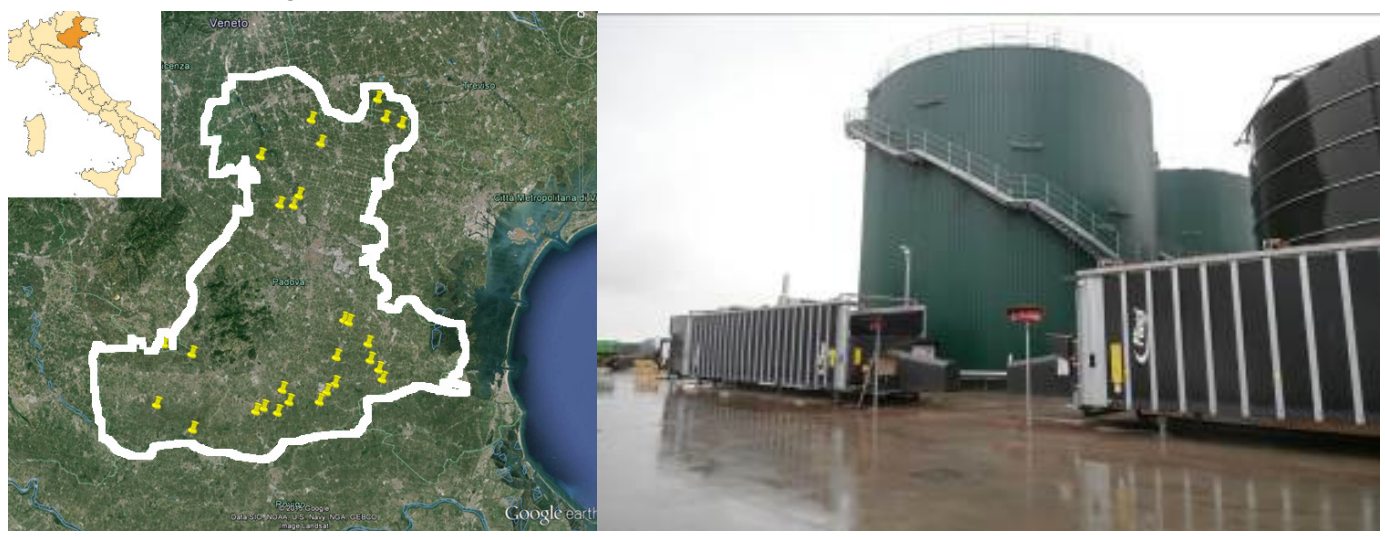

Fig. 1. Localization of biogas plants considered in the survey

\section{Results and discussion}

\section{Installed Powers}

More than $53 \%$ of the monitored plants have a nominal power ranging from 2.2 and $2.5 \mathrm{MW}$, $25 \%$ between 1.3 to $1.6 \mathrm{MW}$ and the remaining $21 \%$ variable to $0.75-1 \mathrm{MW}$ (Fig. 2A). As regards the electrical power (Fig. 2B), most of the plants $(60.7 \%)$ amounted to $0,999 \mathrm{MWe}$, in order to remain in the dimensional limits and to benefit of the maximum energetic incentive. The remaining plants (25\%) are medium in size between 0.5 and $0.6 \mathrm{MWe}$, while only $14.3 \%$ (namely only 4 of the 28 plants) have low power levels, between 300 and $400 \mathrm{kWe}$.

The electrical energy production (about 144,000 MWe per year) is sold to the electricity grid operator (92\%) and only a small part is used for self-consumption ( $8 \%)$.

The thermal installed powers usually vary between 20 and $50 \%$ of nominal power, and are generally included between 1.15 and $1.30 \mathrm{MWt}$ for some of the plants with higher nominal power (Fig. 2C). However, if the electric power generated varies slightly, usually between 38 and $42 \%$ of the installed nominal one, the thermal power generated presents a wider range; in fact, it varies from a minimum of $20 \%$ to a maximum of $50 \%$, with an average of about $38 \%$ of the nominal power.
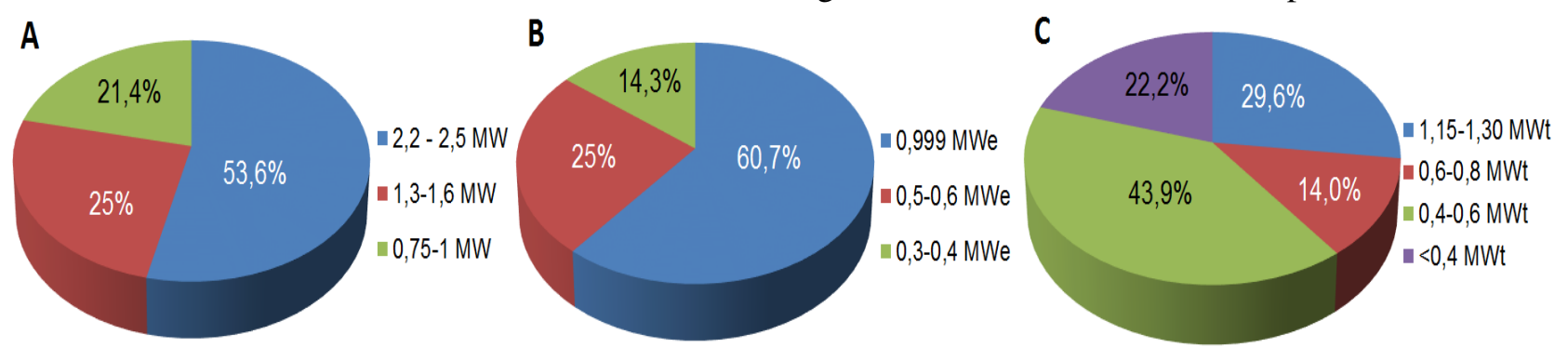

Fig. 2. Nominal power (A), electrical (B) and heating (C) of monitored biogas plants. 


\section{Operative and energy performance}

The plants have operated on average for 350 days (Tab. 1), with about 10 downtime days for ordinary maintenance and 6 days for extraordinary maintenance. These downtimes cause a loss of energy production amounting to $4.1 \%$.

The average of electricity produced during the survey amounts about $8000 \mathrm{MWh} \cdot$ year $^{-1}$ for systems with nominal power from 2.2 to $2.5 \mathrm{MW}, 5074 \mathrm{MWh} \cdot$ year $^{-1}$ for systems from 1.3 and 1.6 MW, while $3173 \mathrm{MWh} \cdot$ year $^{-1}$ for systems between 0.75 and $1 \mathrm{MW}$.

On average, the plants with a nominal power between 1.3 and $1.6 \mathrm{MW}$ have a higher number of non-productive ordinary days amounting to 12.67 days year $^{-1}$, while for non-productive extraordinary days the longest time (days) has been recorded, nearly 8 days.year ${ }^{-1}$, for the plants with a nominal power between 2.2 and $2.5 \mathrm{MW}$.

Table 1

Operative and energy parameters related to the 28 biogas plants monitored

\begin{tabular}{|c|c|c|c|}
\hline \multirow[b]{2}{*}{ Parameters } & \multicolumn{3}{|c|}{ Nominal power range } \\
\hline & 2.2-2.5 MW & 1.3-1.6 MW & 0.75-1 MW \\
\hline Nominal power, MW & $2.44 \pm 0.06$ & $1.45 \pm 0.13$ & $0.9 \pm 0.07$ \\
\hline Electrical power, MWe & $0.99 \pm 0.0$ & $0.62 \pm 0.05$ & $0.38 \pm 0.08$ \\
\hline Heating power, $\mathrm{MWt}$ & $0.90 \pm 0.35$ & $0.56 \pm 0.21$ & $0.37 \pm 0.08$ \\
\hline Daily production hours, $\mathrm{h} \cdot$ day $^{-1}$ & 24 & 24 & 24 \\
\hline Production days, day $\cdot$ year $^{-1}$ & $347.32 \pm 10.04$ & $346 \pm 12.24$ & $354 \pm 4.97$ \\
\hline Non-productive ordinary days, day $\cdot$ year $^{-1}$ & $9.21 \pm 6.21$ & $12.67 \pm 8.17$ & $8.75 \pm 5.19$ \\
\hline Non-productive extraordinary days, day $\cdot$ year $^{-1}$ & $7.97 \pm 4.36$ & $7.67 \pm 5.9$ & $1.02 \pm 2.24$ \\
\hline Electrical energy generated, MWh· year ${ }^{-1}$ & $8044 \pm 614$ & $5074 \pm 366$ & $3173 \pm 819$ \\
\hline Thermal energy generated, $\mathrm{MWh} \cdot$ year $^{-1}$ & $9039 \pm 3938$ & $7750 \pm 3208$ & $3579 \pm 1454$ \\
\hline
\end{tabular}

\section{Feedstock Management}

As regards biomass, the monitored systems use $7.1 \%$ of the arable land in the territory of Padova district. The $93 \%$ of which are represented by cereals, such as maize, sorghum, wheat, rye, triticale, barley and rye grass $(90 \%)$, while the remaining are relative to other arable crops, i.e. soybean and sugar beet.

In relation to livestock manure, only $22.6 \%$ of slurries and manure coming from cattle farms (Fig. $3 \mathrm{~A}$ ) is used for bioenergetics production purposes, while $77.4 \%$ is used within individual farms for agronomic purposes.

For pig farms (Fig. 3B), the share of slurries for bioenergy production purposes reaches $27.7 \%$, probably due to the lower agronomic potential of the byproduct and also to the presence of intensive breeding farms with restricted areas for spreading effluents.

Finally, regarding poultry farms (Fig. 3C), the fraction for bioenergetics purposes seems to be highly reduced $(4 \%)$, probably because this by-product usually contains a high quantity of wood-chip (lignin), and consequently it is not easily degradable during the digestion process.
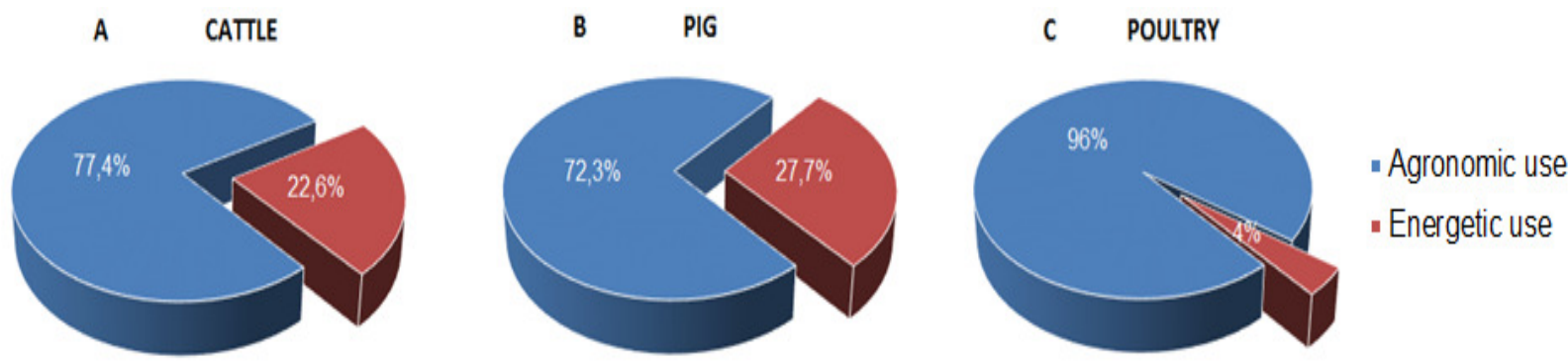

Fig. 3. Energetic or agronomic use of livestock manure: cattle (A), pigs (B) and poultry (C)

About $67.8 \%$ of the total biomass used (Fig. 4A) for plant operation comes from the farms themselves, while the remaining $32.2 \%$ come from other farms or secondary transformers (i.e. agro- 
industrial by-products). This aspect shows a good degree of self-sufficiency, which can be still potentially improved using agricultural by-products or marginal land.

In relation to livestock manure used in the biogas plants (Fig. 4B), $77.1 \%$ is self-produced by the farms themselves, while the remaining $22.9 \%$ comes from other farms, usually located near the plants in order to reduce transportation costs.

A

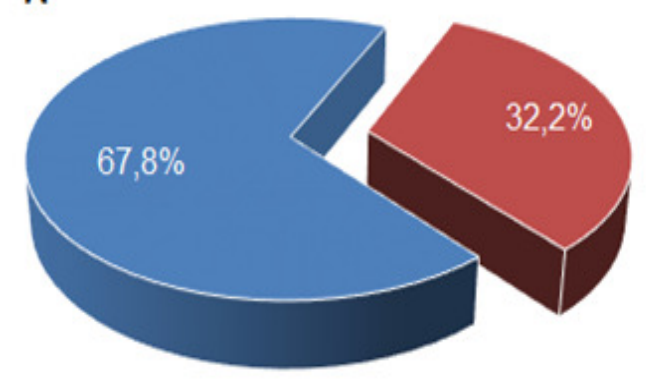

B

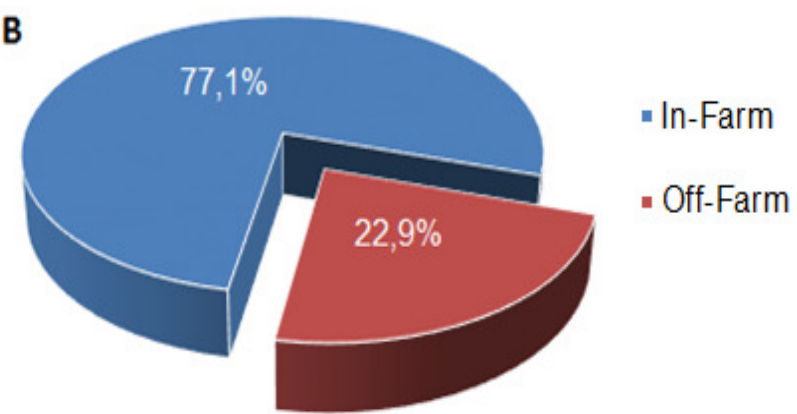

Fig. 4. Biomass farm sources or off-farm sources (A) and livestock manure (B) used in biogas plants

\section{Conclusions}

In this paper, operative data of 28 farm-scale biogas plant localized in the Po Valley (NorthEastern Italy) are summarized and analyzed, as follows.

1. More than half of the biogas plants present a nominal power higher than $2.2 \mathrm{MW}$ and the electric power values, which in $61 \%$ of the cases amount to $0,999 \mathrm{MWe}$, in order to remain into the dimensional limits and to benefit from the maximum energetic incentive. The thermal output values of the plants proved to be very variable, often owing to a non-effective farm-scale valorization of the same.

2. The values in terms of operational performance proved to be positive. In fact, the plants have operated on average for 350 days, with about 10 downtime days for ordinary maintenance and 6 days for extraordinary maintenance.

3. The results suggest a positive outlook for other crops and agricultural waste integration into the $\mathrm{AD}$ supply chain. As for the biomass, the monitored plants are using $7.1 \%$ of arable land in the territory of Padova district, the $93 \%$ of which is represented by cereals, such as maize, sorghum, wheat, rye, triticale, barley and rye grass. In relation to livestock manure, its use varies according to the type of the breeding technique. Most of the effluents utilized for energetic purposes come from pig $(27.7 \%)$, cattle $(22.6 \%)$ and poultry $(4 \%)$ farms.

4. Finally, as regards the biomass origin, the $67.8 \%$ is self-produced at farm-scale, while livestock manure $(77.1 \%)$ comes from corporate farms.

\section{Acknowledgements}

The authors are grateful to Dr. Andrea Gazzin for practical support given during the conduction of the survey.

\section{References}

1. Boscaro D., Pezzuolo A., Grigolato S., Cavalli R., Marinello F., Sartori L. Preliminary analysis on mowing and harvesting grass along riverbanks for the supply of anaerobic digestion plants in north-eastern Italy. Journal of Agricultural Engineering, vol. 46, 2015, pp. 100-104.

2. Pezzuolo A., Boscaro D., Marinello F., Sartori L. Alternative maize ensiling techniques for anaerobic digestion process: economic and energetic comparison. Engineering for rural development, vol. 15, 2016, pp. 959-964.

3. Boscaro D., Pezzuolo A., Sartori L., Marinello F., Mattioli M., Bolzonella D., Grigolato, S. Evaluation of the energy and greenhouse gases impacts of grass harvested on riverbanks for feeding anaerobic digestion plants. Journal of cleaner production, 2017, in press. http://dx.doi.org/10.1016/j.jclepro.2017.02.060. 
4. Basso B., Dumont B., Cammarano D., Pezzuolo A., Marinello F., Sartori L. Environmental and economic benefits of variable rate nitrogen fertilization in a nitrate vulnerable zone. Science of the total environment, vol. 545-546, 2016, pp. 227-235.

5. Pezzuolo A., Dumont B., Sartori L., Marinello F., De Antoni Migliorati M., Basso B. Evaluating the impact of soil conservation measures on soil organic carbon at the farm scale. Comput. Electron. Agric vol. 135, 2017, pp. 175-182.

6. Gissén C., Prade T., Kreuger E., Nges I.A., Rosenqvist H., Svensson S.E., Lantz M., Mattsson J.E., Borjesson P., Bjornsson L. Comparing energy crops for biogas production - Yields, energy input and costs in cultivation using digestate and mineral fertilisation. Biomass and Bioenergy, vol. 64, 2014, pp. 199-210.

7. Cavicchi B. Sustainability that backfires: the case of biogas in Emilia Romagna. Environ. Innov. Soc. Transit, vol. 21, 2016, pp. 13-27.

8. Eurostat. Electricity prices for industrial consumers, from 2007 onwards biannual data. 2017. [online][11.12.2016] Available at: http://appsso.eurostat.ec.europa.eu/

9. Carrosio G. Energy production from biogas in the Italian countryside: policies and organizational models. Energy Policy, vol. 63, 2013, pp. 3-9.

10. Pezzuolo A., Basso B., Marinello F., Sartori L. Using SALUS model for medium and long term simulations of energy efficiency in different tillage systems. Applied mathematical sciences, vol.8, 2014, pp. 129-132.

11. Blengini G.A., Brizio E., Cibrario M., Genona G. LCA of bioenergy chains in Piedmont (Italy): a case study to support public decision makers towards sustainability. Resources, Conservation and Recycling, vol. 57, 2011, pp. 36-47.

12. Marinello F., Pezzuolo A., Gasparini F., Arvidsson J., Sartori L., Application of the Kinect sensor for dynamic soil surface characterization. Precision Agriculture, vol. 5, 2015, pp. 1-12.

13. Bacenetti J., Negri M., Lovarelli D., Garcia L.R., Fiala M. Economic performances of anaerobic digestion plants: Effect of maize silage energy density at increasing transport distances. Biomass and Bioenergy, vol. 80, 2015, pp. 73-84.

14. Dinuccio E., Balsari P., Gioielli F., Menardo S. Evaluation of the biogas productivity potential of some Italian agro-industrial biomasses. Bioresource Technology, vol. 10, 2010, pp. 3780-3783. 